\title{
APRENDIZAGEM CONECTADA: USO DE REPRODUTOR DE MÍDIA COMO FERRAMENTA PEDAGÓGICA NO ENSINO E APRENDIZAGEM DE FÍSICA
}

\author{
Valdinei Cezar Cardoso ${ }^{1}$ \\ Ivani Francisca dos Santos ${ }^{2}$
}

RESUMO: O trabalho traz discussões sobre o uso das mídias como ferramenta para trabalhos pedagógicos experimentais de física com uso de material de baixo custo. Tem como objetivo analisar o uso dos recursos tecnológicos multimídia, em especial o VLC e celular, nas aulas experimentais, como ferramenta pedagógica facilitadora de aprendizagens no ensino de Física. A atividade experimental, analisada neste trabalho, aborda o conteúdo de Física denominado de MRUV, e se subdivide em quatro momentos: organização e orientação dos grupos de estudo, realização do experimento, o uso do reprodutor de mídia VLC e discussões dos resultados. Com a pesquisa foi possível perceber que, ao usar recursos tecnológicos aplicados a aulas experimentais, a aprendizagem se torna mais atrativa e significativa para o educando.

Palavras-chave: Aprendizagem. VLC. ensino de física. reprodutor de mídia.

ABSTRACT: The work brings discussions about the use of media as a tool for experimental pedagogical work in physics using low-cost material. It aims to analyze the use of multimedia technological resources, especially VLC and cell phones, in experimental classes, as a pedagogical tool that facilitates learning in Physics teaching. The experimental activity, analyzed in this work, addresses the content of Physics called MRUV, and is divided into four stages: organization and orientation of study groups, carrying out the experiment, the use of the VLC media player and discussion of the results. With the research it was possible to realize that, when using technological resources applied to experimental classes, learning becomes more attractive and meaningful for the student.

Keywords: Learning. VLC. physics teaching. media player.

\footnotetext{
' Doutor em Ensino de Ciências e Matemática pela Faculdade de Educação da Universidade Estadual de Campinas (2014). Mestre em Educação para a Ciência e o Ensino de Matemática pela Universidade Estadual de Maringá (2010). Especialista em Educação Matemática pela União das Escolas Superiores do Vale do Ivaí (2002). URL da Homepage: www.matematicaaplicada.saomateus.ufes.br.

2 Mestranda no Programa de Pós-Graduação em Ensino na Educação Básica (PPGEEB) - Centro de Educação da Universidade Federal do Espírito Santo (CEUNES - UFES).

E-mail: ivani.santos@edu.ufes.br
} 


\section{INTRODUÇÃO}

Entender conceitos teóricos de física não é fácil para o aluno que chega na I ${ }^{\mathrm{a}}$ série do ensino médio, pois o mesmo tem pouco contato com essa disciplina no Ensino Fundamental. No Currículo do Espírito Santo, em Ciências da Natureza e suas Tecnologias (2020), nos é informado que:

Todos esses componentes estiveram presentes e articulados entre si ao longo do
Ensino Fundamental e na vida do estudante, porém apareciam de forma muito
fragmentada e descontextualizada, como os conteúdos de Biologia, ou em um
único momento, como ocorrente na Química e na Física do $9^{\circ}$ ano, observado nos
PCN e expresso no currículo do Espírito Santo (2009). Currículo do Espirito
Santo (2020, p.2) A compreensão de conceitos físicos, quando discutidos apenas ${ }^{3}$ por aula expositiva, não desenvolve no aluno o espírito investigador que essa ciência é caracterizada. Se os estudantes passam por um conceito sem compreender perfeitamente um anterior, isso cria lacunas em sua aprendizagem (HORN, STAKER, 2015).

As atividades experimentais possibilitam a verificação e comprovação de conceitos teóricos e desenvolvem competências que tornam o sujeito criativo, investigativo e pesquisador à medida que faz conexões entre a teoria e a prática experimental. Assim, "a Física a ser ministrada no Ensino Médio não se propõe simplesmente a descrever um punhado de fórmulas matemáticas desprovidas de significados, sem embasamento teórico ou experimental e aplicações no dia a dia” é o que nos diz o Currículo Básico Escola Estadual (2009).

Segundo Couto (2009, apud GRASSELLI, GARDELLI, 2014, p.8):

As atividades experimentais são consideradas ferramentas eficazes para a contextualização do ensino da Física, abrangendo desde a mera verificação de leis e teorias até experimentos que privilegiam as condições para os alunos refletirem a respeito dos fenômenos e conceitos abordados, visando uma reestruturação conceitual. (GRASSELLI, GARDELLI, 2014, p.8)

O desenvolvimento de experiências realizadas pelos próprios alunos, com o uso de recursos tecnológicos, contribui para obtenção de novos conhecimentos, pois promove momentos de reflexão, avaliação, autoconhecimento e socialização do objeto de aprendizagem. GRASELLI e GARDELLI (2014, p.6) nos fala que é por meio da Física 
Experimental que os alunos são incentivados a raciocinar e a adquirir competências de aplicação dos conhecimentos adquiridos nas aulas teóricas para analisar e resolver problemas.

Os experimentos geram aprendizado quando são compreendidos pelo educando, eles devem representar o conceito oral de um conteúdo físico. Os recursos tecnológicos, quando usados de maneira correta, facilitam o entendimento do conteúdo abordado em um experimento físico. $\mathrm{O}$ estudo experimental, com o uso de um reprodutor de mídia, torna visível o invisível aos olhos do aluno dando sentido ao objeto de aprendizagem observado em um experimento físico.

Este trabalho tem por finalidade apresentar um relato de experiência desenvolvida na disciplina de Física da $\mathrm{I}^{\mathrm{a}}$ série do ensino médio, fazendo uso de reprodutores de mídias digitais como ferramentas pedagógicas para o ensino e fixação de conceitos físicos teóricos e práticos.

O objetivo do estudo é demonstrar que o uso de tecnologias na prática pedagógica do professor de física, que utiliza experimentos práticos em suas aulas, possibilita ao educando analisar, de forma detalhada, o fenômeno ocorrido, contribuindo assim para um melhor aprendizado.

\section{O Conteúdo de Física no Ensino Médio}

O Currículo do Espírito Santo está estruturado por área de conhecimento, a área de Ciências da Natureza e suas tecnologias abrange Física, Química e Biologia, essas disciplinas se desvinculou da Matemática na nova organização curricular do BNCC, configurada anteriormente nos Parâmetros Curriculares Nacionais (PCN) de 1999.

Os conteúdos são distribuídos por série, sendo a Mecânica o objeto de estudo da I ${ }^{a}$ série do Ensino Médio. O conteúdo citado se subdivide em Cinemática, Dinâmica, estática e Hidrostática, sendo a teoria de Galileu para queda dos corpos e princípio da inércia, em Cinemática, o objeto de estudo deste trabalho.

A organização curricular para o ano de 2020-2021 passou por mudanças provocadas pela pandemia da Covid-ı, nesse sentido, com o objetivo de minimizar os impactos da 
pandemia na aprendizagem dos estudantes capixabas, a SEDU estabeleceu o continuum curricular 2020-2021, assegurando a progressão da aprendizagem Orientações Curriculares, Física, Ensino Médio, Atividades Pedagógicas não Presenciais (202I). A proposta para cada trimestre do ano letivo de 2021 está no resgate de conhecimentos e habilidades previstos na série/ano anterior. Nesta organização, o Movimento vertical e a teoria de Galileu para queda dos corpos surgem com a proposta de um trabalho com Filmagem/fotografia de objetos em movimento e análise dos vídeos com o uso do software Orientações Curriculares, Física, Ensino Médio, Atividades Pedagógicas não Presenciais (202I).

A Física é a ciência que estuda, pela experimentação e elaboração de conceitos, as propriedades da matéria e do espaço-tempo.

\section{Recursos tecnológicos: reprodutores de mídia do sistema operacional}

Os reprodutores de mídia, no processo educacional, proporcionam elaborar aulas mais atrativas e interessantes para o educando. Esses recursos possibilitam novas formas de ensinar e aprender, além de expandir as possibilidades e o engajamento dos alunos. Isso porque os conteúdos multimídia apresentam grande apelo visual e encantam pela estética, pelo som e pelo movimento (IMAGINE.EDUCAO, 2021). Atualmente temos muitos recursos tecnológicos que auxiliam no estudo da Física, como os Applets (software de pequeno porte que pode ser executado através de navegadores de internet (CAMILETTI, 20II)), trazem infinidade de simulações de fenômenos físicos.

Dentre os reprodutores de mídias pesquisados (Windows Media Player, VLC Media Player, Winamp e iTunes), para o desenvolvimento deste trabalho, o escolhido, por mim, como ferramenta pedagógica para análise de um experimento físico foi o VLC Media Player.

Apesar dos reprodutores citados acima também oferecerem a possibilidade de reprodução de muitos tipos e formatos de arquivos, o VLC Media Player, ao meu ver, ganhou por alguns aspectos, os quais melhor se adaptaram ao trabalho proposto. Dentre eles posso citar: a gratuidade da licença, pois trata-se de um software de código aberto (OPEN SOURCE), também é um reprodutor multiplataforma disponível para Windows, Windows Phone, Mac, Linux, Android e iOS, o que possibilita o usuário não ficar preso em um S.O (Sistema Operacional) para utilizá-lo, além de suportar um grande número de 
métodos de compressão de áudio e vídeo, assim como formatos de arquivo. O software vem recheado de recursos para atender até mesmo as pessoas mais exigentes, como efeitos de áudio e vídeo. Ele também possui uma versão Portable (Techtudo, 2015).

\section{Atividade experimental: Procedimentos e questões de aprendizagem}

Estudar Física desenvolve o raciocínio, estimula a imaginação, a criatividade e o espírito investigativo. No mundo globalizado e tecnológico, onde a informação está na "palma da mão”, quem domina a ciência está à frente dos demais.

Segundo Giordan (apud SILVA, I; SILVA, A, 2016, p.139) a experimentação caracteriza-se por despertar nos alunos, independentemente do nível de escolarização, a motivação para o estudo.

SOUZA (apud SILVA, I, SILVA, A, 2016, p.139) descreve o experimento como um procedimento planejado, partindo de uma hipótese, que visa provocar fenômenos em condições controladas, observar e analisar seus resultados.

Quanto ao uso de experimentos físicos, Alves (2006, p.12) relata que [...] "novos procedimentos de física certamente são necessários, para motivar a participação dos alunos e aumentar o interesse pelos conteúdos ministrados nas aulas”.

Quanto aos experimentos como atividades pedagógicas, Alves (2006, p.13) nos diz que, "o desenvolvimento de atividades experimentais pode ser uma possibilidade de transição de modelos tradicionais de ensino para a construção de formas alternativas de ensinar física" [...]. Para GRASELLI, GARDELLI (2014) os experimentos:

Promovem as interações entre os saberes práticos e teóricos e, ao mesmo tempo, criam possibilidades para que o aluno estabeleça relações entre o saber já assimilado na construção dos mapas conceituais, como processo altamente facilitador de uma aprendizagem significativa, permitindo assim que se efetive a aquisição de conhecimento. (GRASELLI, GARDELLI, 2014, p. 12).

De encontro com autores, o Currículo do Espírito Santo, descreve como habilidade:

$$
\begin{aligned}
& \text { Interpretar resultados e realizar previsões sobre atividades experimentais e } \\
& \text { compreender a construção de tabelas, gráficos e relações matemáticas para a } \\
& \text { expressão do saber físico de fenômenos naturais e processos tecnológicos, com } \\
& \text { base nas noções de probabilidade e incerteza, reconhecendo os limites explicativos } \\
& \text { das ciências sendo capaz de discriminar e traduzir as linguagens matemática e } \\
& \text { discursiva entre si. (Currículo do Espírito Santo, 2020, p, 22). }
\end{aligned}
$$

Usar metodologias que envolvem o uso de atividades experimentais, requer do profissional que trabalha nesta área, uma postura questionadora, reflexiva, planejamento, motivação e 
avaliação, pois, aplicar uma atividade experimental e usar recursos tecnológicos não é garantia de aprendizado.

\section{I.I Atividade experimental sugerida no livro didático}

A atividade experimental desenvolvida com os alunos da $\mathrm{I}^{\mathrm{a}}$ série do Ensino Médio, da EEEFM Antônio dos Santos Neves, foi sugerida pelo livro didático do aluno/professor, Conexões com a Física, $\mathrm{I}^{\mathrm{a}}$ série, 2or6, cujo autores, Glorinha Martini, Walter Spinelli, Hugo Carneiro Reis e Blaidi Sant'Anna, abordam, na página 6o, uma atividade experimental para o deslocamento no MRU, com uso de material de baixo custo. A atividade proposta pelos autores, figura I, traz um experimento físico, com materiais de baixo custo, a qual foi reproduzida com uso de tecnologia. A princípio a realização da atividade partiu dos alunos, que demostraram

\section{O deslocamento no MRUV}

O objetivo desta atividade é verificar como o deslocamento varia com o tempo em um movimento sujeito à aceleraçăo escalar constante. Para isso, voce vai construir uma pista com dois cabos de vassoura. Certifique-se de que os cabos sâo lisos, que nâo apresentam nenhum obstáculo ao movimento (pregos, farpas na madeira etc.). Vocé também vai precisar de uma bolinha e de um tijolo ou um pedaço de madeira para elevar a pista (veja a figura a seguir). Essa elevaçăo deve ser pequena para que a bola nâo adquira uma velocidade escalar muito grande, o que dificultaria a marcaçăo do tempo.

Materiais

- Dois cabos de vassoura, tijolo ou pedaço de madeira, fita adesiva, bolinha de gude ou de borracha, fita métrica ou trena, cronômetro, régua e papel milimetrado.

Procedimento

1 Junte os dois cabos de vassoura de maneira que suas extremidades fiquem alinhadas e fixe-os com fita adesiva. A pista está pronta e a bolinha deve correr no vão formado pela união dos dois cabos (veja a figura).

2 Marque, na pista, com fita adesiva, distancias proporcionais a quadrados inteiros: 1, 4, 9 e 16. Por exemplo, se a primeira marcação estiver a $7 \mathrm{~cm}$ da origem, a segunda deve estar a $28 \mathrm{~cm}$, a terceira, a $63 \mathrm{~cm}$, e a quarta, a $112 \mathrm{~cm}$. Os cabos de vassoura têm aproximadamente $120 \mathrm{~cm}$, portanto você conseguirá quatro medidas de tempo.

3 Apoie a pista no tijolo ou no pedaço de madeira.

4 Faça no caderno uma tabela para anotar os tempos de cada trecho. Veja o modelo ao lado.

5 Construa um gráfico da posição $\times$ tempo no papel milimetrado.

6 Procure repetir o experimento pelo menos duas vezes para confirmar os dados obtidos.

Questōes

interesse em desenvolvê-la

Figura r: Atividade experimental

Fonte: livro conexões com a Física I ${ }^{\text {a }}$ série do Ensino medio: 
As atividades foram organizadas obedecendo o retorno das atividades educacionais presenciais de forma gradual, em etapas e com revezamento (PORTARIA CONJUNTA SEDU/SESA № or-R, de o8 de agosto de 2020.), e foram subdivididas em quatro momentos.

- No primeiro momento: definição dos grupos de estudo e orientações para a atividade.

- No segundo momento: a realização da experiência.

- No terceiro momento: Uso do VLC.

- No quarto momento: Discussões dos resultados.

\section{Uso do reprodutor de mídia VLC como ferramenta pedagógica no experimento físico.}

O uso TICs na educação tornam as aulas mais atrativas e desenvolve no aluno um sentimento de comprometimento. Segundo Alves (2006, p.13) é necessário que procuremos criar oportunidades para que o ensino experimental e o ensino teórico se efetuem em concordância, permitindo ao estudante integrar conhecimento prático com o conhecimento teórico. O trabalho pedagógico com o uso de experimentos facilita a assimilação dos conceitos físicos. Segundo Pinho-Alves (apud, ALVES, F, 2006, p.I4) o contato entre a linguagem científica, as teorias, o conhecimento, ou o "senso comum" do aluno no processo de experimentação, tornam o ensino de Física mais eficaz e mais próximo do aluno.

O uso do VLC, como tecnologia aplicada na análise de experimento, permite observar de forma detalhada cada etapa do procedimento. Para auxiliar na atividade elaborada, deslocamento no MRUV (movimento retilíneo uniformemente variado), utilizamos o reprodutor de mídia VLC, o qual dispõe de ferramentas que auxiliam na observação, por exemplo, do tempo e percurso percorrido por um objeto em um determinado trajeto, por unidade de tempo. Com a ferramenta, de nome sugestivo, Time, oferecida pelo reprodutor, podemos analisar e obter o tempo decorrido, quase que com exatidão, pelo objeto até pontos específicos do trajeto. Com os dados obtidos podemos, então, plotar um gráfico da Função quadrática de Posição x Tempo. 
Uma das vantagens oferecidas pelo VLC é poder visualizar o experimento com riqueza de detalhes sempre que precisar, como demostra a figura 2.

Figura 2: Uso do reprodutor de mídia VLC para análise do deslocamento do MRUV

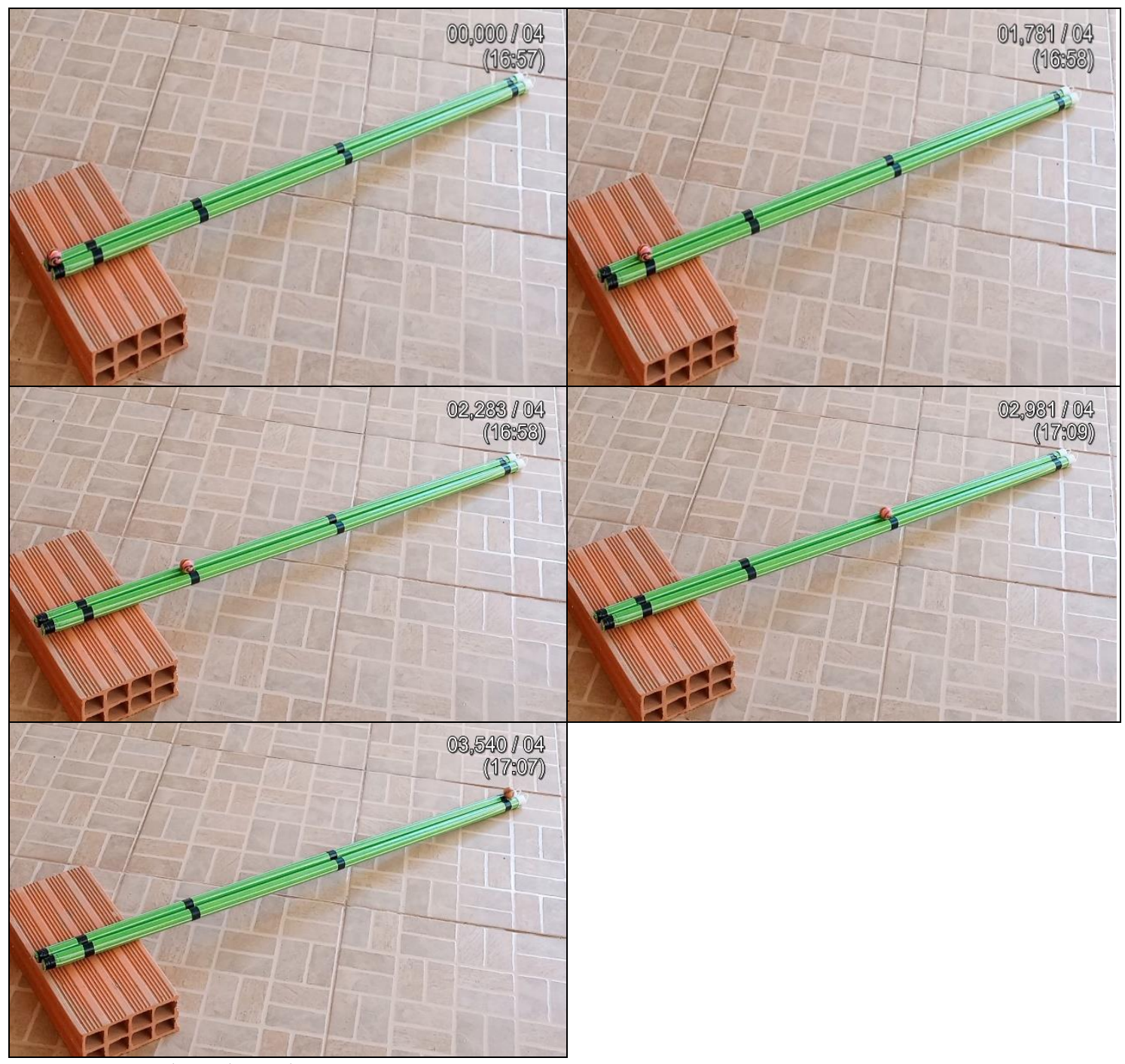

Fonte: Produzida pelo autor

A figura 2 descreve as possibilidades de exploração da atividade experimental, pelo uso do VLC media player. 


\section{Fundamentação Teórica}

Em minha prática pedagógica como professora de Física observei que o experimento físico, seja ele por modelagem, simulação, com ou sem o uso de internet, desenvolve no aluno a curiosidade em ver o que ocorre durante sua realização. Os experimentos são intrínsecos com a prática pedagógica do professor de Ciências Naturais.

Para GRASSELLI, GARDELLI (2014, p.II-I2) o uso de atividades experimentais no ensino da disciplina de Física, de forma especial no Ensino Médio, pode ser considerado um caminho metodológico para a compreensão de conceitos e sua relação com as ideias discutidas em sala de aula com os alunos.

Segundo Alves (2006, p. 25) [...] o uso de atividades experimentais como estratégias de ensino de Física tem sido apontado por professores e alunos como uma das maneiras mais frutíferas de minimizar as dificuldades relativas a aprender e ensinar Física de modo significativo.

Em sua dissertação intitulada: O USO DA HIPERMÍDIA NO ENSINO DE FÍSICA: POSSIBILIDADES DE UMA APRENDIZAGEM SIGNIFICATIVA, Artuso (2006, p.5-6) cita Sousa (2002) com o uso de simuladores no estudo do Eletromagnetismo, Araújo (2002) com o uso software de modelagem para o estudo de gráficos em Cinemática, Gonçalves (2005) com uso de animações e hipermídia no ensino de Física Térmica, Machado (200o) que desenvolveu um software utilizando a linguagem de hipermídia no estudo da Gravitação. As referências citadas por ARTUSO, demonstram que a utilização de tecnologias, no ensino e aprendizagem de Física, aumenta a motivação, o desempenho e o interesse do aluno.

O uso da tecnologia para ensinar física vai além do mero uso de um computador com internet, é necessário traçar objetivos que valorizar os mecanismos mais complexos do pensamento não se fixando em valorização de conhecimentos de fatos que envolvem apenas a memorização, PASSAMAI (2010). Assim, para interpretar resultados e realizar previsões sobre atividades experimentais e compreender a construção de tabelas, gráficos e relações matemáticas para a expressão do saber físico de fenômenos naturais e processos tecnológicos citados no Currículo Básico da Escola Estadual (2009), requer reflexão sobre a prática pedagógica para formar cidadãos capazes de pensar e repensar a ciência e seu valor social para a humanidade. 
FEYNMAM (2004) descreve a Física como a mais fundamental e abrangente das ciências e que exerce um profundo efeito em todo o desenvolvimento científico. A autora nos convida a refletir sobre a abordagem de conteúdos físicos como objeto de aprendizagem, que deve contemplar aprendizagem significativas, que essa ciência requerer na formação humana.

\section{Procedimentos Metodológicos}

Com o revezamento de alunos, a turma da I grupos com I2 alunos em cada grupo. O revezamento é diário, o que dificultou a interação e a troca de experiências entre os alunos.

No primeiro momento, foi discutido como ocorreria a realização do experimento e a organização dos grupos. Foi levado em consideração o revezamento e o retorno do grupo para as aulas presenciais, assim a realização do experimento ocorreu fora do ambiente escolar.

No segundo momento ocorreu a apresentação da realização do experimento, nesta etapa cada grupo apresentou suas impressões acerca da atividade experimental.

O terceiro momento aconteceu no lied da escola e com o uso do VLC Media Player. Nesta etapa o aluno pode perceber a riqueza de detalhes do experimento que realizou com o uso da câmera do celular, projetado no VLC Media Player.

A precisão do tempo e da distância percorrida pela bolinha, permitiu o cálculo de aceleração, explorar a função quadrática e suas possíveis soluções, a função afim da velocidade e suas aplicações na disciplina de Matemática.

No quarto momento ocorreram as discussões em cada grupo sobre a aprendizagem desenvolvida pelo experimento com o uso da tecnologia. Um dos pontos debatidos foi o de responder, de forma oral, se o uso do reprodutor VLC Media Player contribuiu, ou não, no entendimento dos conceitos físicos tais como: aceleração, velocidade e construção de gráfico da função Sxt.

\section{RESULTADOS E ANÁLISES}

O revezamento dos alunos nas aulas presenciais, provocado pela pandemia da Covid-19, mudou a organização e o planejamentos dos momentos de aula, assim a análise do uso do celular e do VLC aplicado na aula experimental de Física ocorreu obedecendo o retorno dos grupos para as aulas presenciais. Para facilitar o estudo, classifiquei os grupos usando 
as letras A, B e C. Cada grupo é composto por 12 alunos. O diálogo dos resultados foi baseado no aprendizado do aluno e no uso dos recursos tecnológicos usados na atividade experimental.

Grupo A: 8 alunos concordaram que o uso do VLC tornou a aula mais dinâmica, atrativa, facilitando a compreensão da resolução das atividades propostas no livro e que eles se sentiram motivados a participar da aula, 2 alunos relataram que precisava de "algo a mais", e sugeriram explorar outras mídias, e 2 alunos não opinaram.

Grupo B: 7alunos relataram que o uso do celular para filmar o experimento foi bom, por poder ver os resultados várias vezes e que o VLC permitiu explorar mais detalhes do experimento ao dar resultados mais precisos. 3 alunos relataram que ajudou, mas que tiveram dificuldades em transcrever o que era proposto nas atividades discursivas. 2 alunos não opinaram.

Grupo C: 7 alunos concordaram que o uso do celular para gravar o experimento foi bom, inovando a forma de trabalhar, e que o uso do VLC possibilitou explorar mais detalhes do experimento, dando valores mais exatos, o que favoreceu o entendimento do cálculo de

aceleração e velocidade. 3 alunos relataram que faltou "algo a mais" e poderia ser explorado outros recursos tecnológicos e 2 alunos não opinaram.

Os resultados apontam, que os recursos tecnológicos, quando usados como ferramenta pedagógica para o ensino e aprendizagem, aumentam o interesse, a motivação e a aprendizagem dos alunos e tornam as aulas mais atrativas.

\section{CONCLUSÃO}

As atividades experimentais, realizadas com materiais de baixo custo, são atividades de fácil realização, que tornam as aulas mais dinâmicas, interessantes e permitem junção da teoria com a prática, dando sentido e significado para o ensino e aprendizagem de Física.

O uso dos recursos tecnológicos, como o celular e o VLC Media Player, aplicados na aula experimental proposta, contribuiu para o entendimento de conceitos do MRUV.

Dos 36 alunos, 61,1\% relataram que o uso dos recursos tecnológicos aplicados no experimento de Física com material de baixo custo, contribuiu para tornar o aprendizado mais significativo e atrativo. 
Concluímos que, as atividades experimentais com material de baixo custo, nas aulas de Física, são atrativas para o aluno e complementam a teoria discutida em sala de aula e que o uso das tecnologias, tão presente na vida dos alunos, agregam valor, interesse, motivação, curiosidade e eficácia ao momento de aula.

\section{REFERÊNCIAS}

ALVES, Valéria de Freitas: A inserção de atividades experimentais no ensino de Física em nível médio: Em busca de melhores resultados na aprendizagem. Brasília DF, dezembro de 2006.

ARAÚJO, Carla de; SOUZA, Eudes Henrique de; LINS, Abigail Fregni: APRENDIZAGEM MULTIMÍDIA: EXPLORANDO A TEORIA DE RICHARD MAYER. UFPB, 2015.

ARTUSO, Alysson Ramos: O USO DA HIPERMÍDIA NO ENSINO DE FISICA: POSSIBILIDADES DE UMA APRENDIZAGEM SIGNIFICATIVA. UFPR - Def. 03/o5/2006, 196f. Universidade Federal do Paraná. Curitiba, 2006.

CAMILETTI, Giuseppi Gava: Informação, Tecnologia e Ciência no Ensino de Física. Vitória: Ufes, Departamento de Física, 20Ir.

Currículo Básico Escola Estadual, Ensino Médio, Volume II, Área de Ciências da Natureza. Secretaria da Educação. - Vitória: SEDU, 2009.

DIÁRIO OFICIAL DOS PODERES DO ESTADO. Secretaria de Estado da Educação SEDU, PORTARIA CONJUNTA SEDU/SESA NNo oI-R- Vitória, o8 de agosto de 2020.

FEYNMAN, Richard P. FÍSICA EM SEIS LIÇÕES, Tradução Ivo Koritowski, Rio de Janeiro, Ediouro, 2004.

GRASSELLI, Erasmo Carlos.; GARDELLI, Daniel: O ENSINO DA FÍSICA PELA EXPERIMENTAÇÃO NO ENSINO MÉDIO: da teoria à prática. Os desafios da escola pública paranaense na perspectiva do professor PDE. Paraná, 2014.

HORN, Michael B. Staker Heather; Blended: usando a inovação disruptiva para aprimorar a educação, Porto Alegre: Penso, 2015. 
IMAGINE.EDUCACAO. Descubra como incorporar o ensino multimídia na sua escola. Disponível em: https://educacao.imaginie.com.br/ensino-multimidia/. Acesso em $28 / 07 / 2021$.

MARTINI, Glorinha; SPINELLI, Walter; REIS, Hugo Carneiro; SANT’ANNA, Blaidi: Conexões com a Física. Estudo dos movimentos, leis de Newton, leis da conservação. Moderna, $3^{\underline{a}}$ Ed. São Paulo, 2016.

PASSAMAI, Maria Hermínia Baião, Fundamentos da educação II: Didática, Vitória: Ufes, Departamento de Física, 2010.

SILVA, Ivanderson Pereira da; SILVA, Alberto Tarrago Marcantonio da: O tema “Experimentos Virtuais” nos Anais dos Eventos Brasileiros de Ensino de Física (2005 2014). UFA. Alagoas, 2016.

Techtudo. VLC Media Player: faça download e reproduza mídias com muitos recursos. Disponível em: https://www.techtudo.com.br/tudo-sobre/vlc.html. Acesso em $25 / 07 / 2021$. 